\title{
Common humanity not common community: The solution to global crisis
}

\author{
Kingsley Okoro N. and Osunwoke Clement I. \\ Department of Philosophy and Religion, Ebonyi State University, Abakaliki, Nigeria. \\ Accepted 25 February, 2013
}

Is a peaceful world an impossible dream? This is one of the most mind wafting questions of the contemporary era. The contemporary period is dotted with both minor and major conflicts and wars. Therefore, scholars are afraid that with the trend and ferocity of the phenomenon, humanity stands the risk of going into obliteration. To check this insidious phenomenon, men developed several sociopolitical and religious ideologies. One of the major attempts towards this direction is the forming of several alliances and unions that will bring individuals together into community. The most important phase of this unionization of mankind is globalization-global village- ideology. This aims at bringing the whole human race into one organic family, with market as the controlling force. Notably, the globalization also known as 'Common Community' in this work did not produce the required miracle as wars and conflicts have become a common place. Against the backdrop of the failure of common community ideology, we therefore propose a new ideology that can yield the peace dividend to the world. This ideology is "Common Humanity". This emphasizes the essence of human nature as a common factor that unites humanity to common fate. It is anchored on care, respect, reciprocity and human values. It accentuates unity in diversity rather than uniformity. This paper, having taken historical as well as documentary survey of the contemporary society, underscores that if shareholders in the world of politics will adopt this common humanity paradigm, humanity, will in short time, experience a peaceful world of her dream.

Key words: Common humanity, common community, solution, global crisis.

\section{INTRODUCTION}

Human history opens with competitive nature of human relationship which results in conflicts and internecine wars. Thus, wars and conflicts are certainly not new in human history. As early as the beginning of human history, world peace was conceived in relation to war. Corollary to the foregoing assumption, system philosophers, with particular reference to Hobbes, become popular with the theory of state or rather the natural state, in which humanity lives prior to the setting up of organized society. In this state of nature as described by Omeregbe (1999), '... There were no laws, no authority, no morality, no sense of right or wrong, and no sense of justice or injustice. Everybody simply pursued the satisfaction of his self interest. Whatsoever satisfies anybody's appetite was for him good and he would pursue it'. In the state of nature, there was no other rule of action than self interest and its satisfaction. In the cause of pursuing personal/self interest men came into conflict with one another, quarreled and fought each other. Thus Hobbes (1946) retorts:

The state of nature was a state of war and insecurity among men, life was insecure, and men were enemies to each other, for conflicts, struggle and war prevailed among men. Man lived in perpetual danger and fear of death ... no knowledge of the face of earth, no account of

*Corresponding author. E-mail: okoro_kingsleyn@yahoo.com. Tel: +234-803-7026069. 
continual fear and danger of violent death and the life of time, no arts, no letters, no society, and the worst of all man was solitary, poor, nasty, brutish and short.

Thus, man in the state of nature was simply an atom in universe of other atoms, a mindless individual in the universe of other mindless individuals. However, fear of going into extinction and being guided by protective logic, men came together to form an organized society/ community. According to Omeregbe (1991), 'They came together and made a social contract, formed a political society and empowered the sovereign to decide what is right and what is wrong, what should be done and what should not be done in the society'. Notably, it was the logic of the local events that drove philosophers and political thinkers to think towards the political evolution that crystallized into centralized government dominated by single sovereign powers dependent on social and economic causes. Agreeably, Hobbes Political writings were occasioned by the civil wars orchestrated by man's greed, selfishness and insatiability. Accordingly, the purpose of community living and political organization is to protect and preserve human life and property. This idea has given birth to different theories of political organizations and the citizen's relationship to the government. The same theory also gave rise to different spheres of political development beginning from the prehistoric period to the present age.

In the present age, known as the age of globalization, the popular cliché is 'community living', 'one world', 'global village', ' family hood of the world community', 'global citizens'. The importance of this cliché is their emphasis on 'Common Community' which will facilitate the peaceful existence of all humankind in a world without boundary. Orji (2004) summarizes these concepts and the process of universalization of ideas, cultures and mankind into one big global family and culture as the growing of interaction of economies and societies around the world as a result of the flow of goods and services, capital, people and ideas. The global village which aims at breaking the boundaries of politics, geography, economies etc- and bringing together all humanity into the world's one big global village -was developed through observation that electronic media contract the world into a village or tribe at the same time. Corollary to the observation, Aina (1996) 'considers the ideological/ political shift as the process of making it global, being present worldwide, at the stage of the world'. Technically, this phase in the political history of mankind is known as globalization. This phase involves the definition of the world activities through the paradigm of commerce, production, consumption, politics and information technology, whether in the realms of ideas, values, institutions, practical experiences and human interactions.

The global village ideology entails therefore the universalization of values, whereby the objects, practices and values transcend geo-political boundaries and penetrate the hitherto sovereign nation-state and impact on the orientation and value system of the indigenous people. The process grants freedom, ability and capacity to individuals by initiating voluntary economic transactions with residents of other countries (Okoro, 2006). Generally, globalization summarizes a number of inter-related features of economy, which anchors on rapid advance in communication and transport technologies, expanding spatial scope of business activities in private corporations and financial institutions, the integration of markets across borders and a high degree uniformity in policy and institutional environment that sets the rule for the game for economic actions and interactions or the part of private agents based on various countries (Ajayi, 2004; Okoro, 2006). The major concern of the new community (global village) process is to break down national boundaries, weakening of state powers, privatization, deregulation and trade liberalization. It is the assumption of the new ideology that the dislocation of the boundaries of the state, limiting their financial control, sovereignty of nations and employing the invisible hands of market as the supreme order of the world will facilitate the integration of the hitherto separate states, indigenous communities, race and people into one global family.

However, humanity generally has discovered to their greatest dismay that the hope of peace and tranquility expected as the dividends of joining the global community has become an illusion or rather a night mare due to incessant crises, internecine wars, global terrorism, classism, oppression and intimidation of the poor people and nations. Therefore, Linder (2012) bemoans the current world crises situation as she laments, "the future of mankind is at stake". In collaborating Linder's assumption, Houtart (2011) writes, 'All around the world, there is deep unease caused by the growing divisions in society, lack of respect for justice, youths' unemployment, abuse of power, destruction of nature... the economic development model that we have, with its political, cultural and psychological consequences is at the origin of these imbalances'. To this, the World Council of Churches (WCC) in Harare in 1998 adds that:

Injustice and inequality have taken new and more aggressive form. Many people are dying of poverty today than ever before. Unacceptable levels of poverty today than ever before. Unacceptable levels of poverty co-exist with small pockets of wealth between and within nations. Mother earth is groaning because of the many ways in which we continue to exploit her... can we remain comfortably silent when over three billion of God's people are caught in the web of poverty and death?

However, it is quite undeniable that amidst the chaotic situations, we humans have a deep yearning for peace, though presently we live in a world which is marked by discord, dissension, hatred, violence and war. Faced with this painful situation, the most searching and pertinent questions are: can we really hope for peace? Is 
humanity capable of ushering in an era of peace on earth? If it is capable of doing so, then what are the basic resources open to her? It is against this backdrop that this paper posits that the main resource available to this age long quest for peace is humanity itself. This demands going back to the core issues of human nature and relationships with one another. It underscores that the solutions to human predicament is not in eternal forces artificially created by man himself, rather in the intrinsic nature of man. The basic essence of human nature and origin ought to be revisited for proper re-examination in order to underscore the existential realities of common humanity as the only solution to world crisis.

\section{Common community ideology}

The idea of building a common human community is not a recent development. In fact, it dates back to the $15^{\text {th }}$ century. Razu (2000), reducing common community ideology to a simple category, which he called globalization, opines that it has been observed that globalization process did not originate in the contemporary economic history. The core of globalization can be theoretically conceived as the near culmination of a process that began with the dawn of European expansion and the modern world system 500 years ago. Okoro (2006) was explicit in maintaining that common community, technically known as globalization began in about $15^{\text {th }}$ century with the rise of capitalism and its oversea expansion. In his own words, "common com-munity process started with the conquest and exploitation of Africa, Asia and Latin America. In this direction, Conzalez (1999) points out that the process had a long history even in the America and Europe and as such attributed the origin of the phenomenon to the arrival of Christopher Columbus in America. He states the position inter alia:

It is not the first time globalization (common community) process has been experienced. The arrival of Columbus in America probably meant major globalization, However that was the first time it was experienced with a number of characteristics propelled by technological revolution and extraordinary factor accelerating the globalization of our current age.

Following the assumption of Conzalez, the globalization common community - had a long history at least in European continent. Thus, the benchmark in defining the historical boundaries of common community - globalization is the event that marked the arrival of Columbus into Europe. It is against the backdrop of this assumption that made Bodner (1998) to assert that globalization actually existed long before the term became fashionable. The phenomenon in the recent times connotes the intensification of the worldwide relations, which links distant localities in such a way that the happenings are shaped by events occurring many miles away and vice versa (Konrad, 2002).

However, the nature and dynamics of the common community ideology took a new dimension and new emphasis in the recent days. Thus, Khan (2004) defines the new nature and new dynamism of the socio-political and economic phenomenon as he maintains that after the September 11, 2001 episode, the very discourse of international relation and global politics became transformed. Notably, prior to September 11, the dominant issues were geo-economic in nature, globalization (common community) and humanitarian issues occupied the agenda of international summits and international organizations. Now geo-politics and security concern have once again become central issues and the old language and institutions of cold war are shaping our thinking about geo-politics (Okoro, 2010). Thus prior to the eventful and most dreaded historical dating September 11, the world with the aim of averting conflicts among members of the global community began to move rapidly to realizing the ideas of the global commonalities in terms of economic aspirations and technological progress, which were emphasized by politicians and world leaders (Okoro, 2010c).

In his own contribution, Chumakov (2010) opines that by the $21^{\text {st }}$ century both separate countries and humankind as a whole have accumulated theoretical and practical material allowing them to understand the problems common for the whole of humankind. This therefore made the interest in common community (globalization) to become intensified. However, many scholars and world citizens are still confused about the origin, nature, process, definition and direction of the global village phenomenon. Hence, Chumakov (2010) avers, "Most people are unable to approach globalization not only as a collusion of interest and a struggle of various international actors but as an objective process dating back to past centuries. Actually, this particular understanding is simple and quite necessary in appropriating the development of common community ideology that humanity as a whole has been caught in its webs. The relevance of this approach in understanding the phenomenon is predicated on the fact that globalization did not begin in the $20^{\text {th }}$ century; when it engendered global problems, it became a real threat to humankind and attracted universal attention. In the idea of Chumakov (2010), it began much early, at the intersection of the $15^{\text {th }}$ and $16^{\text {th }}$ centuries in the era of the great geographic discoveries.

According to this assumption, the process started with the first circumnavigation undertaken by Magellan which had finally shown that the earth was orbicular and that man's living space was limited (Avril, 2008). It began after the event and sphere in human history, when world land and ocean had become accessible; first of all for Europeans and then for all people of the planet (Chumakov, 2010). However, the first attempt to 
understand the world as an organized whole may be found in the works of Karl Marx and Frederick Engels, Kant, Danilevskii etc in about $18^{\text {th }}$ century. Though the globalization ideology was still hazy as most scholars just regarded the notion of global holism as premonition or yet unclear of the nature of global interconnectedness. It was in the works of Marx, Kant and Engels that one finds intuitive insights regarding the universal interconnectedness of the animate, the inanimate and the social that has become a contemporary dictum. These scholars stood at the threshold of the world as an organized whole. Chumakove (2011) aptly describes the process thus:

In this regard, one may point to Thomas Malthus'es' idea of natural regulation of population number to Kant's idea of everlasting peace, to Lamarck's Concept of biosystemic evolution and man's role in it. Apart from targeting specific problems and separate trends trespassing national boarders, this period is characterized by the first attempt to represent the whole world history as a self regulatory and progressive evolving process. Such position was typical of Kant with his universal history concept. However, only Karl Marx and Friedrich Engels were able to make full use of this approach in their materialistic historical construction.

Notably, it was Marx that first undertook an attempt to doing a deeper analysis of economic, political and cultural globalization and used such in various communities as a paradigm of judging human relationship in socio-economic spheres. So it was Marx that first embraced the historical process in its wholeness and unity. He studied history from the standpoint of economic transformation of society. Thus in the words of Ivan (2003), Marx's theory of socio-economic formation is nothing else but the first historical attempt to cognize the pattern of social development from its primordial, prehistoric forms to the emergence of a united, holistic, planetary society embracing all people. Overtly, Marx and Engels understood not only the fact that economic relations were becoming global but also that international relations and even the sphere of spiritual life were becoming universal too (Chumakov, 2011). Though they may not have used the term 'global relations' it was evident from 1848 communist manifesto that they stressed the universal nature of capital relations. According to them, the Bourgeois has through its exploitation of the world market, given a cosmopolitan character to production and consumption in every country. Thus, in place of old local and national seclusion and selfsufficiency, we have intercourse in every direction, universal interdependence of nations, as in material, so also in the intellectual production. The intellectual creations of individual nation become common property. The national one-sidedness and narrow mindedness became more and more impossible and from the numerous national and local literatures, there arose a world literature. It took 100 years for this thought that reveals the essence of globalization - common community - to become evident for broader public consciousness (Chumakov, 2010). However, at the dawn of the $21^{\text {st }}$ century, the ideology assumed world consciousness and this is evident in the speeches of two world leaders. Hence, the speeches of Mikhail Gorbachev and George Bush on the matter became a benchmark for any meaningful discussion on common communityglobalization- ideology. Hear Gorbachev as he speaks:

We are witnessing most profound social changes, whether in East or South, West or North, hundreds of millions of people, new nations and states, new public movement and ideologies have moved to the forefront of history. Broad based and frequently turbulent popular movements have given expressions in multidimensional and contradictory ways to a longing for independence, democratizing the entire world order has become a powerful socio-political force. At the same time, the scientific and technological revolution has turned many economic, food, energy, environment, information and population problem. Due to the advances in the mass media and means of transportation, the world seems to have become more visible and tangible. International connections have become easier than ever before (Manuel, 2010).

Now let us hear George Bush as he affirms thus:

...A new partnership of nations has begun and we stand today at a unique and extraordinary movement. The crisis in the Persian Gulf as grave as it is also offers a rare opportunity to move towards historic period of cooperation. Out of these terrible times, our objective - a new world order- can emerge. It is a new era free from the threat of terror, strongest in pursuit of justice and more secure in the quest for peace. An era in which the nations of the world - East, West, North and South can prosper and live in harmony. A hundred of generation has searched for this elusive path to peace, while a thousand wars raged across the span of human endeavours. And today that new world is struggling to be born; a world quite different from the one we know, world where the rule of law supplants the rule of jungle justice, a world in which nations recognize the shared responsibilities of freedom and justice, a world where the strong respect the rights of the weak (Manuel, 2010).

The speeches of these two great world leaders betray the sense in which a new world, which places premium on community, is born. This phase in human history and development is expected to fast track the union of nations, peoples and cultures. In fact, this union is the basic nub of the global village arrangements that has become a modern cliché. This new process of social 
rebirth, which the entire humanity is waiting for, would have moved rapidly towards the realization of the ideals of the common community, where our differences in the forms of religion, culture, ethnicity, race, sex etc will not be remembered anymore. Thus, the common community ideology suffices the ultimate celebration of the political, economic and social hegemonization of the world population (Okoro, 2010). Zygmunt (2011) sustains the foregoing assumption as he opines, "The social state is no longer viable, only a viable social planet" may take over the functions of the social state tried with varying degree of success to perform. Accordingly, there are valid reasons to suppose that a globalized planet on which the plight of everyone everywhere determines the plight of all the others; while being determined by them, one can no longer assure and effectively protect democracy, "separately" in isolation in one country or in a few selected countries only. Thus the fate of freedom and democracy in each land is decided and settled on the global state - common community- and only on that stage it can be defended with realistic chance of a lasting success (Zygmunt, 2011).

At this point, Zygmut (2011) scores another milestone in the development of the utopian common community among the global citizens. This milestone hinges on his understanding and consequent definition of democracy using his Yaroslavaina Context and AGORA category as his matrix. Accordingly, democracy is a form of life of the agora: of that immediate space which links/separates the two other sectors of the polis - ecclesia and oikos. In Aristotle's words, "Oikos" stood for family, household, the site inside which private interest was formed and pursued. Ecclesia stood for the public - for the popular council composed of the elected, appointed or drawn by the magistrates, whose function was care of common affairs that affect all citizens of the polis, like matters of war and peace, defense of the realms and the rules governing the cohabitation of citizens in the city - state, having originated from the verb, 'kalan' meaning 'to call", 'to summon', 'to gather'. The concept of ecclesia presumed from the beginning the presence of 'agora' the site for democracy (Galbraith, 1992). It is from this interpolation that he affirms the development of one world community of people. It is assumed that the inherent conflict within the social order will be diminished if the socio-political and economic boundaries and national sovereignty are broken down to give way for universal citizenship controlled not by the superman, the prince or the philosopher - king but the unseen hands of the market. However, this new visions seems to be a mirage because the real human experience is the exploitation and demoralization of majority of humankind by the minority of the rich and powerful and facilitated by the social system, where power is concentrated on the hands of the rich and influential few. This therefore calls for a new social political paradigm to change the present situation.

\section{The basic problems of common community ideology}

All around the world, there is deep unease caused by the growing divisions in the society, lack of respect for justice, Youth unemployment, abuse of power, wanton destruction of nature... when more than 900 million human beings live below the poverty line, while their members keep increasing (UNDP, 2012) when every 24 hours tens of thousands of people die of hunger or the consequences, when day by day, ethnic groups ways of life and culture are disappearing endangering the very heritage of humanity, when the inequality between man and woman is reinforced in the formal and informal economic system, when the climate is deteriorating. When all this is happening, it is simply not possible to talk only about conjectural financial crises, even though such crisis exploded violently in 2008 (Houtart, 2011).

The basic assumption of the neo-liberal economic system, which is the engine of modern globalization, is that through its operation, humanity shall smoothly be brought into a peaceful global community. However, this assumption seems to be one of the delusions of the modern era. Thus Okoro (2010) writes "It is now obvious that modern globalization has failed in all spheres to unite the people and break the inequality gaps between nations and people of the global community. It is worthy of note that the ideology that runs the modern globalization or rather the 'common community' agenda of the modern world seeks to legitimize the concentration of multifaceted power structures - neo-liberalism-this ideology drives neo-liberal and neo-liberal globalization. In this regard, neo-liberalism provides an ideological cloak for the project of economic globalization that expands power and domination through an interlocking web of international institutions, national policies, corporate and investor practices and individual behaviours. In essence, neo liberalism runs human being into commodities and reduces the role of national government to secure harmonious and sustainable social development. It places utmost emphasis on private capital and so called unfettered markets to allocate resources and promote growth (WCC, 2005).

Generally, economic globalization is centered on capital neo liberalism, which transforms everything and everyone into a commodity for sale at a price. It makes competition its dominant ethics and throws individuals against individuals, enterprise against enterprise, race against race and country against country. With regard to material wealth and human dignity, the system dehumanizes human beings and sacrifices life for greed. It is therefore an economy of death (WCC, 2005). In this same direction, Zygmunt (2011) maintains that the underlining factor of the present globalization of inequality is the current repetition on a planetary scale of emancipation of business interest from all extant socio-cultural institutions of ethically inspired supervision and control 
and consequently the immunization of business pursuits against all other values than the maximization of profit. Since the aim of modern globalization is the maximization of profit rather than equality of human beings within the global family, it therefore widens the gap between the rich and the poor nations of the world. In the words of Moneyhams (1975), 'The new economic order created and promoted poverty to an uncontrollable state in the global village'. He went on to define poverty sternly thus:

Poverty is ... looking into the future devoid of hope. It is an acid that eats human pride until pride is burned out. Poverty is being tired - dog tired at all times. Poverty makes one pretentiously polite. The poor cannot afford to offend those who might give him something. Poverty makes one older than his real age. It is a chisel that chips at honours until the honour is pulverized. Poverty is like a bleeding wound which never heals, hemorrhaging strength and life out of the body and contributing to the chronic sickness of the society.

In his attempt to relate Moneyham's definition of poverty to the contemporary experience of mankind in the society, McNarnara, one of the presidents of World Bank (WB), asserts that by 2005 two-thirds of mankind (over one billion) individuals are entrapped in this web of poverty. The consequence therefore is that it severely limits the right of these individuals to the basic necessities of life (Okoro, 2006). Thus Moneyham affirms the reality of poverty in the modern world by presenting his facts thus, 'These millions of mankind are caught in the grips of hunger and malnutrition, high illiteracy, inadequate education, shrinking opportunities and corrosive poverty with the effects that young men will turn into armed robbers and women have become prostitutes'

Therefore, the present global citizens live in an era of dangerous paradoxes. The neo-liberal economic paradigm of "global free markets" has amassed more material wealth than ever in the hands of a very small minority. The very processes of wealth creation have engendered massive inequalities and high destabilizing trends. The lives of the poor are sacrifices for the gains of the rich. The WCC (2005) document presents a statistical data of these global inequalities thus:

Today 1.5 billion citizens of our planet, the majority of whom are women, children and indigent people live on less than one dollar a day, even as the world's richest 20 percent account for 86 percent of global consumption of goods and services. The income of the richest $1 \%$ is equal to that of the poorest $59 \%$ and 24,000 people die each day from poverty and malnutrition

The basic reason for the polarization of the global family into two classes - the rich and the poor - with the latter constituting the majority of the population is herein given by Nwachukwu (2004): "No one or rather only few (if any) would go into economic collaboration for loss. Against this backdrop, Uka (2004) describes the current economic system as a short hand name for imperialism, domination, exploitation, marginalization and over all, reproduction of injustice, inequality and poverty.

From the foregoing discussion, it has become pertinent to note that the architects of the common community agenda - globalization- are not seeking to uphold the dignity of all members of the earth community. They do not seek to maintain the balance of interests of the members of the global village. They do not seek to ensure the equal participation of all and to maintain the liberating interdependence of all. They also do not seek to promote good custodianship of the earth nor do they seek to promote justice for all. It was Perkin's (2006) confessions (John Perkin was one of the members of America Economic Hit Man) (EHM) that made us to draw such conclusion:

We in EHMs ... build empire, we utilize international financial organizations to ferment conditions that make other nations subservient to the corporatocracy running our biggest corporation, our government and our banks. Like our counterparts in Mafia, EHMs provide favour. These take the form of loans to develop infrastructures .... A condition of such loan is that engineering and construction companies from our country must build all projects. In essence most money never leaves the United States. It is simply transferred from one bank to the other in the United States. Despite the fact that the money is returned immediately to corporations that are members of the corporatocracy (the creditors) the recipient country is required to pay it all back, principal and interest. If EHM is completely successful, the loans are so large that the debtor is forced to default on payment after few years. When this happens, then we demand a pound of flesh. This include among other things access to precious resources and of course the debtors still owe us the money and by this another country is added to our global empire (2006).

Therefore, globalization ideology is simply a law of the jungle applied to economies and society. The strongest and the fittest will survive (Razu, 2000). These are some of the basic assumptions of the current socio-economic system that runs the world:

1. That only those who have property or may participate in contracts have right to participate in the economy and society.

2. A world where individuals and corporations are motivated by their self interest and where society is merely an aggregation of self-serving individuals.

3. Economic growth through 'free' markets is paramount. Neo-liberalism claims that only through this economic model can poverty be eliminated, sustainable developed 
ensured, gender equality achieved and the millennium development goals finally met.

4. That deregulation of labor markets is essential to creating new jobs and opportunities for workers in a competitive global economy

5. That economic growth that requires a dynamic process of 'creative' destruction in efficient activities is allowed to die, while successful enterprises emerge taking advantages of new technologies.

6. That the economic, social and personal trauma that are caused by 'structural adjustment' programmes are justified as short term pains necessary for long time gains. The newly created wealth will eventually trickle down to the poor

7. The markets are always more efficient than the state. Neo-liberalism assumes that good governance exists where government liberates markets and restricts its sovereign right to determine its own policies through privatization, commercialization or enforcement of 'free trade' agreement. Failure to comply with these policies and the failure of these policies once implemented to produce their promised benefits are blamed on "bad governance" rather than on neo-liberal model itself

8. That free markets, free trades, self regulation and competitions will liberate the invincible hands of the markets for the benefits of everyone.

9. That integration into the global economy will ultimately benefit every nations and empower every individual even if some make greater gains than others (WCC, 2005).

However, from the realities of human experiences, it could be underscored that the concept of economic globalization as presented by its proponents is clouded in deceptions. Let us consider some of the assumptions presented above and see how they square up with contemporary experiences.

1. An economy of life is also embedded in people's social, cultural and political realities and not on selfism of individual and corporate organizations like the present order.

2. Creation including mankind has spiritual essence; God's given intrinsic values and purpose that cannot be commodified. This is against the logic of the marketism and liberalization of goods and services.

3. People concrete experiences show that market-driven economy is inequitable, unsustainable and irreconcilable with economic justice and caring economy.

4. International divisions of labour visibly rewards an elite of property owners and promotes a race to the bottom for the majority of the world population through deunionization, structural unemployment, exploitation in free trade zones and contemporary forms of slavery.

5 . There is no obvious pattern of continuous restructuring that is designed to maintain and enhance the profit of global corporations by sacrificing people and earth. "Creative destruction" in fact promotes the survival of the fittest and the non-survival of the weak and contradicts the religious vision of care and love for the poor and the vulnerable.

6. The experience around the world is that "structural adjustment" re-distributes wealth and power from the poor to the rich and deepens structural inequality. This unbearable reality amounts to an economic philosophy of human sacrifice.

7. The most fundamental understanding of democracy, justice and self determination underlines that the only way to secure genuine government is through the regulation of capital and markets to secure the needs of the people, as defined by the people themselves.

8. To suggest that markets have saving powers amount to idolatry. In any scale, markets are not free. The myth of "unfettered" unregulated, uncontrolled market capitalism is everywhere being challenged by the realities of human experience. The reality is that markets and capital are highly controlled to secure the maximum benefits for the owners of capital. Liberalization forces and capital market form social obligations and are therefore immoral and irresponsible by definition. This freedom is achieved through the agency of the states dominating the international institutions of IMF, World Bank, World Trade Organization (WTO)

9. The legacy of new liberalism is the deepening of inequality of wealth and power between and within nations and also instability, resentment, resistance and rejection increase the global economy resembles earlier eras of colonialism that depended for protection on mounting levels of repression and militarization. In other words, as market becomes global, so do the mechanism that protects them. In recent years, we have seen the dramatic convergence of economic globalization with political and military hegemony in power network.

In summary, common community ideology- modern globalization, in all its penetrative forms of westernization, socialization, democratization, consumerism and growth of market capitalism represents an onslaught against the less privileged people in the conservative culture (Edward, 2010). Against the backdrop of this striking revelation, many people feel numb and powerless in the massive misuse of mal - distributed economic and political power and arrogant use of military force (WCC, 2008). The implication of the above critical survey of the common community agenda styled globalization is that the whole agenda has brought untold hardship to majority of the global citizens. Thus globalization is regarded as ontological cousin of violence. In fact, globalization does not only breed violence, it is violence personified. Therefore, the common community ideology is simply an ideology of class system. Ibhawoh (1999) subsumes thus:

... but even at that, the World Bank and IMF conceded that whatever macro-economic gains that have been 
made have come at the great social cost and those gains have not always been manifested in micro-economic terms. In other words, even in countries where structural adjustment has been implemented, the living conditions of the common persons have not improved significantly, if anything, they have deteriorated.

The overall effect or rather achievement of socio-cultural and economic globalization of the $21^{\mathrm{st}}$ century is collective selfishness by disrespect, exploitation and avid violence towards the outsiders of the corporatocracy. This attitude dictates the behaviours of the corporate elites commanding the global economy and the result is inequality within the global village community and this propels conflict, terror, violence and breach of peace within the global family (Okoro, 2010). The sum of the whole discourse hinges on the revelation that it is this deception and falsehood of the common community ideology that is responsible for the contemporary conflicts and terrorism. This is because when marginalized people are pushed to the wall with no hope for the future, they react with violence against the system that they may blame for their fate. Thus, the need for a new global vision based on humanity rather than on economics is an urgent necessary.

\section{COMMON HUMANITY: THE SOLUTION TO THE CURRENT WORLD CRISES}

Everything in the universe, everything from the simplest known particle of matter to the most complex of conceivable life forms is simultaneously a whole in its own right and a mere part of something larger, wider, more encompassing and more whole. To understand the whole we need to understand the parts and to understand the parts we need to understand the whole (Kunnumpuram, 2007).

The citation above is simply an interpretative form of understanding planetary existence. This means that all lives within the planetary system are part and parcel of the unit whole and all are interlocked in the unitary web of existence. Okoro (2012) makes the idea more explicit when he writes, '... a starting point for addressing the monumental understanding needs begin with the recognition that all forms of life are connected to the central life support system. The recognition of which could create a shift in that thinking that leads to the emergence of holistic consciousness' (Okoro, 2012; Collins, 2011). This ideology presents to us once again a hermeneutic circle of understanding relationship within the planetary system and it is within the hermeneutical circle that the master motion of existence can be best understood (Wilber, 1997). Thus the relative wholeness and the simultaneous wholeness of everything that exists is held together by the hermeneutical tension between four basic principle: agency, communion, transcendence and dissolution (Kunnumpuram, 2007; Wilber, 1995).

Agency refers to the relative autonomy of a unit of existence. It tends towards the ability for self definition, self preservations, self assertion and enhancement. Communion refers to the partness aspect of a unit of existence, which makes it dispose to and capable of responding to the well being of the larger whole of which it is a mere part. It also refers to the ability to accommodate, adjust, surrender and even die to itself in consideration of the larger whole. Existence, on its own, is made possible and healthy as maintained through a constructive tension between these principles of agency and communion. On its own, transcendence is that propensity observed in all open system, animate and inanimate, to emerge developmentally superior, more complex and more encompassing structures and forms, while dissolution refers to the propensity for vertical breakdown along essentially the same part through which transcendence travels. For instance, when a human being dies, the animate body becomes inanimate and breaks down to molecules and atoms (Kunnumpuram, 2007). This understanding of interconnectedness and interdependence of all lives in the world will make human beings involved in the modern dialectical tension of death and survival to chart a new path to healing the fragmentation that has bedeviled the modern society. This requires a new human consciousness that encompasses a more holistic outlook of existence. In the words of Ervin (2004), 'The new holism tells people they are not machines, however complex and sophisticated and timely separated from each other and their environment. Humans are consciousness elements in the dynamic universe interacting with each other as well as the biosphere. Similarly Okoro (2011) writes:

What is the truth about this world? It is not in the mass of substance, nor in the number of things but in their relatedness, which neither can be counted nor measured nor abstracted. It is not in the material, which is many but in expression which is one. All our knowledge of something is knowing it in its universe; in that relation that is truth. A drop of water is not a particular assortment of element, it is the miracle of harmonious mutuality in which the two reveals the one ... There is the dancing ring of season, the elusive play of lights and shadows, of winds and water, the many coloured wings of erratic life flirting between birth and death. The importance of these does not lie in their existence as mere fact but in their language of harmony; the mother-tongue of our soul through which they are communicated to us.

In the same direction Mayore (2005) writes:

To be human is to try to go beyond oneself, to join with a greater sphere of life in sacrifice, love and friendship. Men must find, feel and represent in their creative work, 
man the eternal, the creator ... for reality is the truth of man, who belongs to all times. Man is eager that his feelings for what is real to him must never die. Here it must find an imperishable form.

The common humanity idea of our dream is the understanding that transcends all narrowly defined identities, noting specifically that human individuals are simply a unit of consciousness in the cosmic or universal consciousness. This embodies the essence of universal minds, the uni-versal man and the supreme personality or the God of humanity in the cosmic consciousness. It is the under-standing that there is a common bond of spiritual unity that binds the whole of mankind (Tagore, 2008). The common humanity ideology as a fundamental option of human relationship underscores a balance of social dynamics between individuals, gender and social groups in harmony with nature in order to promote life and ensure its reproduction (Houtart, 2011). Accordingly, Hourtart (2011) underscores the construction and application of the common good of humanity as a whole which means in the first place, respect for the wholeness of nature as the source of life (the mother earth). He also noted that this is a process of being rather than theoretical academic discussion. He states inter alia, '... The fundamental elements of the collective life of humanity on the planet are process not just academic exercise but something to be worked out in society where thinking has an essential place; but so does practical experience particularly with the social struggle'.

In this regard, Lindner and Dorothy (2010) define the common humanity paradigm as a practical reality that is achievable in the modern society as they point out that the key to the ideal human relationship should shift from "a great turning point to a great learning point". It is the need to look for right relationship. Here, they spotlight that the earth charter, which is amenable to all entails a message about living with oneself and others. This brings about the consequence of transforming all system breakdowns into a system of break-through - moving from safe and healthy communities to a scarce and healthy planet from stake-holders to shareholders (Linda, 2012). Linda, explaining the science of right relations, underscores a practical step as she says, "I do not wish for peace; I live for peace. Peace is the goal, it is not the outcome. We are the connective tissues'. According to Lindner and Dorothy (2010), right relationship does not mean economic truimphism, that is, the substratum of the current socio-political system but ending humiliating practices and achieving human dignity through the conscious generation of right relationships. Here, they generated seven categories with which the world could move towards achieving the common humanity ideology. These seven categories shall be adopted as our model in this paper:

Relationship not in western ideology: It is important to realize that we are not conceptualizing "Right relationships" in western dualistic terms (of Good and bad relationships), we are simply striving for a more complex understanding of right relationship.

Right relationship and healthy growth: It should be understood that "right relationship" must facilitate the healthy growth and development of all involved. Right relationship is characterized by mutual empathy, mutual empowerment and movement towards mutuality. By mutuality, we do not mean relationship that involves exchange or reciprocity. Rather, mutuality means both or all people in the relationship are growing even through mutuality; they may be growing in different ways. A lack of movement towards mutuality in relationship is a clue that the relationship is not the right one.

Relationship as a sense of equality: Right relationships are characterized by a sense of equal dignity and equal worth. All people in the relationship feel valued and there is an understanding that everyone has something they can contribute to the other person, the relationship or the situation, even though they contribute in different ways.

Right relationship makes room for authentic living: Right relationship makes it safe enough for people to be real, to be authentic, to bring more of themselves into the relationship. In right relationship people do not hide large part of themselves in order to stay in the relationship.

Right relationship provides empowerment: In all right relationship real sense of empowerment means feelings that one can have an impact on the other people, the relationship and the situation.

Right relationship energizes the people: Right relationship energizes both and/ or all the people in the relationship. This is in contrast to one-way relationships in which one person gains energy (power, benefits etc) at the expense of the others.

Right relationship cultivates optimal function: Right relationship cultivates optimal function of both and/ or all people in the relationship. Right relationship are not just idea, they are supremely practical way to build a better world for all of us. When people are not absorbed by protecting and defending themselves against hurtful brutal relationship, they can use their energy to create solutions to addressing the enormous problems we are facing in the world today.

The emergence of the modern state system is still historically evergreen in our memory. The modern state system that has become the matrix of socio political and economic relationship did not develop on mutual understanding and relationship of parties involved in the 
social relationship, rather, it was artificially created from the 1948 treaties of Osnabruck and Munster- known as the peace of Westphalia (Linda, 2012). The treaties were based on the socio-political theories of the state and citizens couched by Thomas Hobbes, John Locke and Jean-Jacques Rousseau and their ideas of social contract (Andrew et al., 2010). The social contract in theory and practice involves rights and duties, with the citizens being more or less passive objects and the state being the active object (Linda, 2012). However, with the emergence of marketism (market-economy) in the wake of the $20^{\text {th }}$ century, the dice upturned, as both the citizens and the state assume passive position and the market occupies the active position and became the figure of Adam's Smiths invisible stands. This accounts for the marginalization of both the citizens and the states that are at the fringes of world economy and crisis; conflict and terror have become the existential experiences of the modem state as a consequence of being ruled by the mindless invisible hands of the market.

However, our common humanity ideology aims therefore at making Adams Smith's invisible hands visible and useful for all rather than for small elites (Linda, 2012). This new social relationship model represents an interesting emergent field and supported by new information communication technology (ICTs) and fact of a global reality of non-market practices. This approach rearranges the order of prioritizing the people and culture. It was Fiske (1991) that first enumerated this category. These four models of Fiske are also adopted in this work as universal though elementary forms of organizing most aspects of sociality. These models are (1) communal sharing (CS), (2) Authority Ranking (AR), (3) Equality Matching and (4) Market Pricing (M P) (Fiske, 1991). Notably, family life is often informed by communal sharing, trust, love, care and intimacy fostered at this point and in its context. Authority ranking involves asymmetry among people who are ordered along vertical hierarchical social dimension. Equality matching implies a mode of balance such as in-turn-taking and market pricing builds on a model of proposition with respect to ratios and rates (Linda, 2012).

Therefore to build a decent and a dignified society, which centers on humanity rather than community, Fiske's four models must be taken with seriousness. The central idea in this model is the maintenance of equilibrium of the social relationship. Here the maintenance of unity in diversity is the core of the model. In this regard, Fiske (1991) defines unity in diversity as avoiding oppressive uniformity as much as divisive fragmentation. This unity in diversity protects dignity against big oppressive government that forces everybody to become same, as much as against under-regulation that obliterates diversity through might is right; freedom that reintroduces the humiliation of the abuse of ranks or rankism (Robert, 2003). Diversity can best be safeguarded through everybody uniting around the task of giving equal dignity to all. Linda (2012) technically called the process 'equalization'. In her own words, "I have coined the term "equalization" to denote unity in dignity and overcoming of rankism through unity in diversity". The global community to be harmonious requires equal rather than unequal antecedent to dignity and respectful treatment for all its members. Since inequality is inherently unstable, practicably norms such as human rights advocate the opposite and the pressure of the security dilemma wanes.

Thus a new mode of relationship within the global family different from globalization has to be borne. Linda (2012) called the new mode "Globegalization", while Okoro (2006) calls it Glolocalization. Linda defined her mode in vivid terms thus,

In practice globegalization means creating institutions at the global level that safeguards space for diversity at the local level. These institutions have the common good of humanity at large at heart and enforced by communal sharing. Within such frames, authority ranking or rankism, equally matching and market pricing are embedded in ways; the way they serve the good of all humanity

Similarly, Okoro (2006) defines his concept of glolocalizations thus, using Nigerian contexts.

Nigeria (world) leaders must re-define the concept of globalization, with the aim of making (Nigerians) global citizens but act locally. The outcome of the redefinition shall be glolocalization. Thus, if the concept of glolocalization is adopted as a model of relationship in the global village, it will help in redefining the type of global village we have in mind. By definition a village is a small separate unit connected to other units. It is of different shapes and diverse characters. It is a mosaic and not a neat uniform system. The global village is very much present in the local diversity and non-conformity is the hallmark of African Village Ideology (25)

The common humanity ideology should in practice reject every form of common community that denies plurality of culture. Notably, plurality provides the space for different realities and identities to grow in dialogue. Whenever the space is denied, the marginal people suffer acutely. The struggle of the marginal people for identity is to be regarded as a necessary process to realizing the common humanity ideology which should be the matrix of human relationship within the utopian global village.

\section{Conclusion}

It is no gainsaying that the modern socio-political and economic system has destroyed the fabrics of human relationship which in the cultural milieu, was centered on care, love, reciprocity, born of the fact of human equality. 
It did this by introducing a dialectical method of economy, which has polarized human beings into two classes, the rich and the powerful and the poor and the powerless. The implication of the polarization is placing a cutting edge on human social life as it places premium on material achievements of human beings as means of judgment. The system has sacrificed social capital at the altar of economic capital thereby reducing human being to the status of mere commodities and market wares or chattels. Thus man lost dignity and honour and primarily his status of control in the universe. The socio-political and economic system has reduced majority of the human population into the state of abject poverty as over $57 \%$ of human population live on or below a dollar per day. It has also elevated very few elites to an enviable state of affluence, while reducing the rest to the state of subhumanity, as they face the risk of death and extinction. The precarious situation therefore calls for reconstruction of the entire world system to have a human face. This means the redefinition of human relationship from 'Common Commu-nity' paradigm to 'Common Humanity' paradigm.

It is against this backdrop that Hourtart (2011) writes, 'as the destructive globalization of capitalism has exercised its supremacy in the economies, societies and culture of the world without however totally eliminating their specific characteristics - the reconstruction task belong to us all, men and women according to our facial characteristics and historical experience'. The task of making the human anthropo-culture is the task of all. No one is excluded in the common efforts to redefining the necessary conditions for life. The paradigm of humanizing rather than materializing our world is not in fact new as it may seem. Notably, in the pre-capitalist societies all around the world there are references to it, that is, to a holistic vision of human destiny on earth. In many cases this is expressed in religious terms and traditions with philosophical base - Taoism, Confucianism, Hinduism, Judaism, Christianity, and Islam - as well as in the traditional religions of the indigenous peoples. The main task is simply the question of discovering the appropriate visions and concrete practices in contemporary terms for the diverse societies of today. It is therefore common humanity and not common community that can bring solution to the virulent world crisis.

\section{REFERENCES}

Aina TA (1996). "Globalization and Social Policy in Africa" In Research Netword CODESRIA Bulletin pp.1-39.

Andrew S, Johnson V, Peter C (2010) Growth is Not Possible, Why We Need A New Economic Direction. Totness Sehumacher College No Act www neverconoomics.org/sites newecononics org/peles/growth mist possible.

Avril SN (2008). "European Forum" Philosophical Bulletin No 58.

Chumakov AN (2010) Philosophy Of Globalization In Selected Articles. Moscow M. Maus Press.

Collins M (2011) The Global Crisis and Holistic Consciousness, How Assertive Actions Could Lead To Creation of An Improved Future. In
Conscious Connectively. Creating Dignity in Conversation (Ed) Brenner Michelle Lexington KY Create Space Publications pp.214223.

Conzalez F (1999). Europe and the Globalization: Towards a European Project. New York: Maogkrou.

Edward W-WS (2010). Globalization and Transnational Ideology. Essay Pennsylvania.

Ervin L (2004). 'Mind and matter: The New Holism and Greater Humanity' In the Great Adventure Towards a Fully Man Theory and Evolution (ed) Loye D. Albant New York State University.

Fiske Alan Page (1991). Structure of Social Life. The Four Elementary Forms of Human Relations. New York Free Press.

Galbraith JK (1992). Culture of Contentment. Boston: Houghton Mufflin.

Hobbes T (1964). The Leviathan. Oxford: O. U. P.

Houtart F (2011). From Common Goods to the .Common Good of Humanity. Brussels. Rosa Luxamburg Foundation.

Ibhawoh B (1999). "Structural Adjustments Authoritarianism and Human Rights" In Africa. Journal of Comparative Studies of South Asia, Africa and Middle East. 19:158-167.

Ivan MI (2003). Global Studies. Moscow: Raduga Publishers.

Khan MMA (2004). Globalization in the Era of Terrorism. Richmond: University of Richmond Press.

Konrad R (2002). For a Culture of Life: Transforming Globalization and Violence. Delhi. CSS Books.

Kunnumpuram K (2007). World Peace: An Impossible Dream? Bombay: St. Paul Society.

Linda M (2012) The Crisis of Modern Age: Humiliation of Humankind. Miami: Florida University Press.

Lindner EG, Dorathy S (2010). "Dignity or Humiliation in Economics and Monetary Systems: Towards A System of Right Relationship" A Paper Presented At the $13^{\text {th }}$ Annual Conference of Human Dignity and Humiliation Studies (Human DHS) World Peace through Humiliation - Free Global Human Interactions in Honolulu. Hawaii, August 20-22, 2009

Manuel T (2010) "Terrorism as anti-Globalization. file/edu.com downloaded on 07/06/2010(1-7).

Moneyham J (1975). What Do You Say to A Hungry World? Texas: WACO Press.

Nwachukwu DN (2004). "The Effect of Globalization on African Woman" A Paper Presented at the International Congress on Global Economy and Pastoral Care and Counseling and Religious Traditions at Bangalore. India, August 8-15, pp.1-10.

Okoro KN (2012). 'African Concept Of Inochi: A New Paradigm for Peace Education in The Contemporary Society' In International Journal For Humanities and Social Sciences (Online) Vol. 2, No 1 August, 2010 (Accepted for Publication).

Okoro KN (2011). "Towards a New World and New Humanity: Rabindranth Togore's Model. In Conscious Connectivity Creating Dignity In Conversation (Ed) Michelle Brenner. Lexigton KY Create Space.

Okoro KN (2006). Religion, an Instrument of Checking the Ills and Harnessing the Blessing of Globalization in Nigeria. An Unpublished Doctorate Thesis Submitted To the Department Of Religions and Philosophy, University of Calabar, Nigeria.

Okoro KN (2010c). "Religion and Terrorism: A Socio-Historical ReConsideration In Journal of Alternative Perspective in Social Sciences

(JAPSS) 1(2):82-93

Omeregbe JI (1991). A Simplified History of Western Philosophy Vol. 2. Ikeja: Joga Educational Resource Publication.

Orji K (2004). "Globalization As Imperialism Its Implication For Development In Democratic Nigeria" In Sophia An African Journal Of Philosophy. Calabar, Department Of Philosophy, University of Calabar pp.18-29.

Perkin J (2006). Confession of an Economic Hit man.wwwJonyperkins confession com. Downloaded on June 21, 2006.

Razu MJ (2000). "Globalization as Victimization: A Critique In The Light of Jubilee Motif: The Case of India" The Bible Speaks Today: Essay in Honour of Ghana Robinson (Ed) Muthunayagon D. J> Delhi: ISPCK.

Robert WF (2003). Some Bodies and No Bodies: Overcoming The House of Rank. Gabriola Isiland BC New Societies. 
Tagore R (2008). Balancing the Local and The Universal COA News Tuesday 03 June, 2008 1416am www transitional respective org. Retrieved on $02 / 10 / 2012$.

Uka EM (2004). "Impact of Globalization on The Third World Economy: A Gospel Response" A Paper Presented At The International Conference In Global Economy and Pastoral Care and Counseling and Religious Traditions At Bangalore. India, August 8-15, pp.1-10.

Wilber K (1995). Ecology, Spirituality: The Spirit of Evolution. Boston: Shembhala.
Wilber K (1997). The Eye of The Spirit: An Integral Vision For A Word Gone Slightly Mad. Boston: Shamdshala.

World Council of Churches Documents (2005) "Alternative Globalization, Addressing Peoples And Earth (AGAPE). Geneva: Justice, Peace and Creation Team.

Zygmunt B (2011). "From Agora to the Market Place and Where To From Here" J. Global. Stud. 2(1):3-4. 